\title{
CONSIDERAÇÕES CONCEITUAIS E METODOLÓGICAS SOBRE PROJETOS DE EDUCAÇÃO PATRIMONIAL
}

\section{A U T O R}

\section{Prof. Dr. Fábio Vergara Cerqueira}

Historiador, Doutor em Antropologia Social. Departamento de História da Universidade Federal de Pelotas

Contato: fabiovergara@uol.com.br

\section{Jezuína Kohls Schwanz}

Pedagoga e Especialista em Memória, Identidade e Cultura Material. Mestre em Memória e Patrimônio, Universidade Federal de Pelotas. Professora Pesquisadora da Universidade Aberta do Brasil/Universidade Federal de Pelotas

Contato:jezuinaks@gmail.com

\section{Luísa Lacerda Maciel}

Licenciada em História e Especialista em Educação. Mestranda em Memória e Patrimônio, Universidade Federal de Pelotas. Tutora da Universidade Aberta do Brasil/Universidade Federal de Pelotas

Contato: luisamaciel@gmail.com

\section{Mariciana Zorzi}

Turismóloga, Mestranda em Memória e Patrimônio, Universidade Federal de Pelotas

Contato: mari.zorzi@gmail.com

\section{RES U M O}

E D U C A Ç Ã O

PATRIMON I A L :

S E N S I B I L I Z A R

P A R A

P R E S E R V A Ç Ã O,

F O M E N T A R

\section{A U T O E S T I M A}

O presente artigo tem como proposta apresentar algumas considerações teóricas e metodológicas sobre educação patrimonial. Coloca como objetivos maiores sensibilizar para a preservação e fomentar a autoestima. Toma como premissa a escuta da comunidade e como metas o reconhecimento das comunidades no patrimônio e o estímulo à tolerância. Entre as potencialidades, destacamos a capacitação dos agentes sociais para a preservação, a participação das comunidades e o despertar de vocações profissionais. São colocados alguns paradigmas para orientar a educação patrimonial na escola e a pesquisa prévia que deve ser feita sobre o patrimônio cultural local, visto em sua multiplicidade. Por fim, assume-se o compromisso com o "empoderamento" das comunidades, no sentido de garantir o direito à cultura e à memória coletiva, e, valor supremo, com a pluralidade social e a diversidade cultural.

Palavras-chave: museus de arqueologia, estágio em história, comunidades.

Um dos principais objetivos que motivam a educação patrimonial é, por meio de abordagem inclusiva, o fomento à autoestima das comunidades locais, estimulando o conhecimento e valorização de seu patrimônio, memória e identidades culturais. Paralelamente, busca sensibilizar as comunidades para a preservação de suas variadas formas de patrimônio material e imaterial, que constituem suportes de sua memória e identidade cultural. (GONÇALVES, 2004: 19. FUNARI, PELEGRINI, 2006. CERQUEIRA, MACIEL, ZORZI, SCHWANTZ, 2007: 87-88)

Esta sensibilização é necessária para se efetivar a preservação do patrimônio cultural, em termos amplos. É necessário salientar que o olhar e parecer do técnico - arquiteto, historiador, arqueólogo, antropólogo, historiador da arte, restaurador, etc. - é indispensável para que as políticas de salvaguarda e conservação do patrimônio não se baseiem na superficialidade, 
E S C U T A R A

COMUNIDADE,

ES T I M U L A R O

RE C O N HECIMEN TO

E A TOLER Â N C I A

nos modismos e no senso comum, muitas vezes incapazes, pela falta de formação profissional, para o reconhecimento das peculiaridades dos bens culturais e para a aplicação das medidas adequadas à conservação e eventual restauro destes bens. (CERQUEIRA, 2008: 13-16) Isto poder parecer óbvio, mas não o é para a grande parte de administradores municipais dos pequenos e médios municípios de nosso país: seguem utilizando profissionais sem formação nas áreas patrimoniais para as funções públicas e execução das ações de preservação.

De outro lado, é mister ressalvar que a intervenção do técnico por si só não é o bastante: impõe-se que haja o envolvimento da comunidade, do público. $\mathrm{A}$ população diretamente envolvida com os bens culturais patrimonializados precisa conhecê-los e reconhecer-se neles. Lembremos das palavras atribuídas a Aloísio Magalhães (1997: 190):

A comunidade é a melhor guardiã do patrimônio. [...]

Só se protege o que se ama, só se ama o que se conhece. [...]

Este reconhecimento, da comunidade no patrimônio, deve se dar em dois caminhos complementares, traçados entre o local e o global: pela trajetória particular desta comunidade (identificando estes bens como parte de sua história), mas também pela capacidade de sentimento de pertença a bens entendidos como da humanidade (identificando-se, por meio de bens pertencentes em sua origem a outros grupos, como responsável e guardiã deste patrimônio).

A educação patrimonial, ao mesmo tempo em que deve estimular o conhecimento e valorização dos testemunhos culturais e identitários das comunidades locais, deve também encetar nelas o sentimento de tolerância para a diversidade cultural, a sensibilidade para admirar a cultura dos outros povos, de outras regiões e outras épocas, cujos registros culturais expressam a riqueza da cultura humana. (DECLARAÇÃO DA UNESCO SOBRE A DIVERSIDADE CULTURAL, 2001, Pressupostos n. 3 e 4 e Artigo $1^{\circ}$ ).

POTENCIALIDADES:

C A P A C I T A Ç Ã O,

P A R T I C I P A Ç Ã O, VOCAÇ Õ $S$
Assim, a educação patrimonial tem a potencialidade de propiciar aquilo que está além das prerrogativas do técnico: 1. pode capacitar a população para fiscalizar e cooperar com a conservação dos bens culturais; 2. pode capacitar a comunidade para participar do processo de eleição dos bens culturais a serem patrimonializados e incluídos nas políticas e financiamento voltados à sua conservação, restauro e sustentabilidade; 3. pode promover o envolvimento e identificação das comunidades com os bens patrimonializados, por meio do conhecimento e do estímulo à participação nos processos decisórios; 4. pode estimular o surgimento de novas vocações, despertando interesse pelas profissões relacionadas à preservação do patrimônio cultural. (CERQUEIRA, 2008: 14)

De forma idealista, podemos imaginar que a educação patrimonial seja um instrumento importante para a construção de uma democracia cultural em escala planetária, baseada em formas de cidadania que se sustentem na valorização de 
Na primeira década do século XXI, a escola, em decorrência da constatação da importância social da educação patrimonial, foi colocada diante de um impasse: ao chamar para si a responsabilidade pela promoção da educação patrimonial entre os jovens e crianças, constatou a dificuldade de inserir em seu cotidiano a educação patrimonial, que deve ser necessariamente multidisciplinar e indispensavelmente participativa - precisa não somente introduzir entre os educandos conceitos e informações técnicas, mas, sobretudo, semear a sensibilidade para o patrimônio cultural, para que, em futuro próximo, possamos colher os frutos de uma sociedade mais comprometida com a valorização de seu patrimônio, de sua memória e de sua identidade. (MENDES, 2002: 504)

Para tanto, é indispensável que os projetos de educação patrimonial sejam precedidos de mecanismos de escuta, em que se possa diagnosticar a percepção que as comunidades-alvo possuem do que seja conceitualmente patrimônio e do que seja o seu patrimônio. (Figuras 1, 2 e 3) Do ponto de vista pedagógico, existe aqui, portanto, um princípio freiriano, pois a educação patrimonial fundamentada exclusivamente em conhecimentos técnicos exógenos à percepção e memória de uma determinada comunidade estaria fadada a não conseguir sensibilizá-la, a manter-se apartada da sociedade e responsável pela manutenção de mecanismos de exclusão social, o que não deveria ser o objetivo da educação patrimonial. (ZAN, 2003: 13).
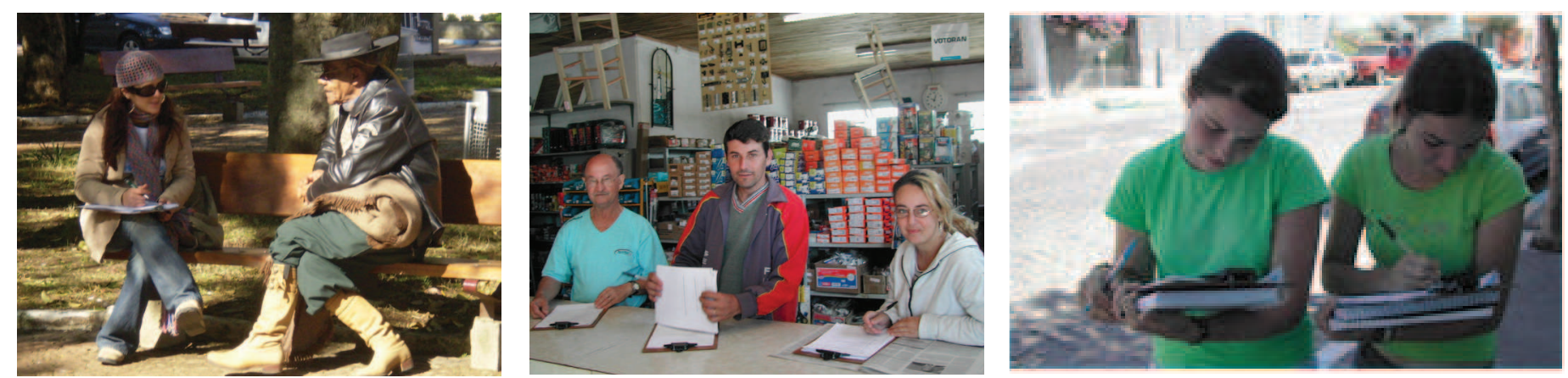

Fig. 1: Bagé. Fig. 2 e 3: Arroio Grande. Fonte: Banco Cultural - Programa Memoriar - LEPAARQ/UFPEL

\section{Figuras 1, 2 e 3}

Conversar com moradores ou aplicar questionários estruturados, no comércio ou na rua, com adultos ou jovens, são algumas das alternativas para realizar a escuta das percepções locais do patrimônio cultural.

Um dos objetivos da educação patrimonial, para a consolidação de uma cultura patrimonial, é capacitar os educadores, bem como profissionais de outros setores envolvidos com a questão patrimonial (gestores, jornalistas, etc.) a manusearem alguns princípios e informações básicas sobre o universo jurídico-conceitual do patrimônio, assim como a se movimentarem dentro do universo multidisciplinar constituído pelas várias formas de patrimônio. Estes são profissionais multiplicadores que, com a capacidade de manusear ferramentas básicas em termos de cultura patrimonial, podem exercer um papel multiplicador.

Aqui se coloca a constatação de que uma das maiores deficiências que se verifica na aplicação continuada da Educação Patrimonial entre a população escolar encontra-se na maior necessidade de capacitação dos educadores. Este problema foi apontado por Débora Coimbra Nuñez, em sua análise da situação da Educação Patrimonial nas escolas municipais da cidade mineira de São João del Rei (NUÑEZ, 
1Programa Regional de Educação Patrimonial da Região Sul do Rio Grande do Sul, executado pelo Laboratório de Ensino e Pesquisa em Antropologia e Arqueologia da UFPEL, desenvolvido entre 2005 e 2008, por meio do convênio "Arqueologia e Educação Patrimonial da Região Sul do RS", firmado entre a UFPEL e a empresa Votorantim Celulose e Papel, aplicado em 12 cidades da fronteira meridional riograndense (Aceguá, Arroio Grande, Bagé, Candiota, Capão do Leão, Cerrito, Herval do Sul, Hulha Negra, Jaguarão, Pedras Altas, Pedro Osório, Pinheiro Machado e Piratini).

U M A CONDIÇÃ O : PESQUISA PRÉ VIA

DAS FORMAS E

PERCEPÇÕES DO

PATRIMỐNIO LOCAL
2011: 60-87). Do mesmo modo, as avaliações produzidas ao longo dos quatro anos de desenvolvimento do Programa MEMORIAR ${ }^{1}$ indicaram, como se constatou na fala dos participantes, o desejo e necessidade de uma capacitação mais profunda do professor, dado o despreparo para lidar com o campo multidisciplinar do patrimônio cultural.

A aplicação, na escola, de práticas pedagógicas multidisciplinares é uma condição para o desenvolvimento da educação patrimonial: a temática do patrimônio cultural, assim como a temática ambiental, demanda um tratamento transversal, que participe das instâncias formais e informais da educação escolar, que flua entre o cotidiano da sala de aula e as atividades extra-classe, prevendo inclusive a visitação aos bens culturais, por meio de passeios, exercitando-se a faculdade cognitiva do olhar, como sentimento humano de fruição e intelecção do patrimônio.

De forma precedente ou paralela à aplicação de um programa educativo, tanto em escolas como em eventos, deve-se realizar uma etapa destinada ao levantamento dos Bens Culturais Materiais e Imateriais das comunidades, pois não se pode considerar viável uma ação educativa qualificada, voltada ao Patrimônio Cultural, que dispense o estudo direto destes bens nas comunidades envolvidas, inclusive a própria percepção que estas possuem sobre o seu patrimônio. (LIMA FILHO, SILVEIRA, 2004: 40)

A pesquisa sobre o Patrimônio Cultural deve se sustentar na interpretação de fontes diversas, de natureza escrita, oral, visual e material. (CERQUEIRA, MACIEL, ZORZI, SCHWANTZ, 2007: 92) Entre as fontes históricas escritas, destacam-se os documentos oficiais e jornais locais. No que se refere à oralidade, a técnica da História Oral constitui-se em uma boa opção, aplicada junto aos moradores mais antigos das comunidades locais, que têm muito a contar sobre suas trajetórias de vida e sobre a história da cidade. No campo da visualidade, é produtivo inventariar algumas fotos antigas. O registro fotográfico é utilizado igualmente para inventariar expressões materiais do Patrimônio Cultural, nomeadamente a diversidade do patrimônio construído, bem como objetos arqueológicos ou museológicos identificados. Por meio de procedimento fotoetnográfico, a fotografia pode também documentar o patrimônio imaterial, ao registrar performances de produção e fruição do saber fazer (Figura 4), de jogos (Figura 5 e 6), de sociabilidades, de valores.

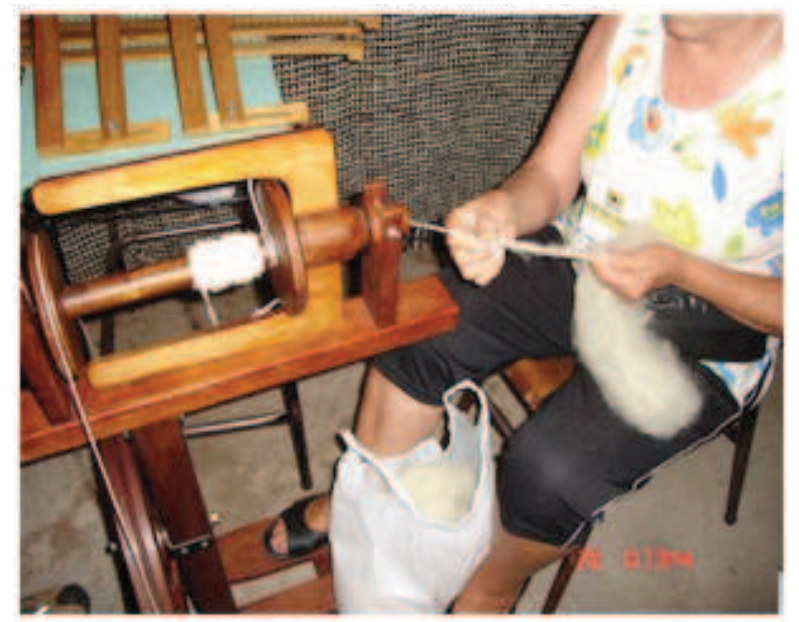

Figura 4

Uso de tear tradicional. Retomada do saber fazer da tecelagem artesanal a partir da lã de ovelha XXIII FEOVELHA, Pinheiro Machado/RS (2007) 

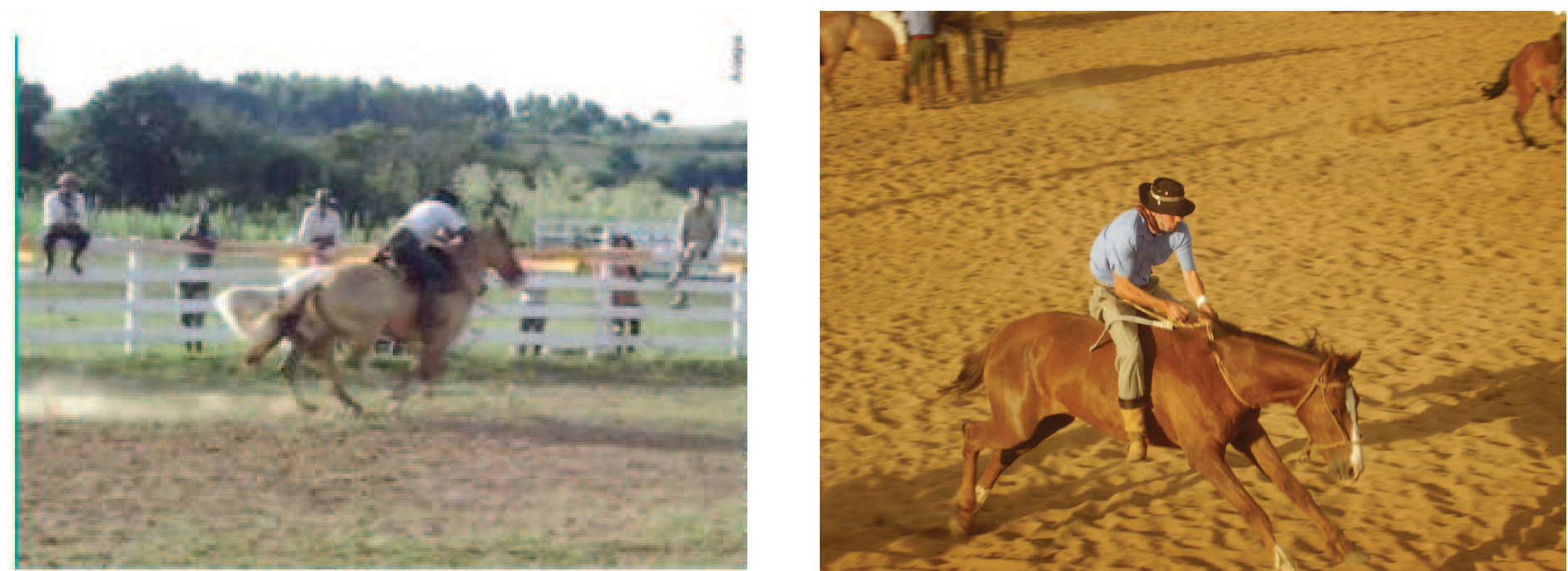

Fonte: Banco Cultural - Programa Memoriar - LEPAARQ/UFPEL

\section{Figuras 5 e 6}

Competições eqüestres. Tradições campeiras gauchescas.

Fig. 5: XXVIII Expofeira de Ovinos, Herval do Sul/RS (2006)

Fig. 6: VI Festa Internacional do Churrasco, Bagé/RS (2007)

O conjunto destes dados forma um Banco Cultural, que constitui uma ferramenta indispensável à organização de encontros e de exposições: através dele se podem montar as apresentações multimídias utilizadas nas ações educativas. Quando o educando olha a sua cidade representada em imagens, diferentes leituras são feitas. A praça é vista de um novo ângulo, cores e formas, e deixa de ser um simples local de encontros e brincadeiras para ganhar um novo sentido. A arquitetura, os detalhes, um banco da praça... Novos olhares atentos de crianças e adultos, que passam a perceber de formas diferentes o Patrimônio Cultural que está presente no seu cotidiano. "Não importa a cidade, cada um olhará a partir de suas relações com o lugar, pois sempre estaremos aprendendo com ela e ressignificando a partir de nossos referenciais" (GALVANI, 2005, p. 160).

Os desenho e maquetes do patrimônio, feitos pelas crianças que participam de projetos de educação patrimonial, revelam esta sensibilização do olhar. Conforme Edith Derdyk (1989: 118): "O ato de desenhar se dá no presente imediato. Para a criança presente seria o desejo impulsionando a ação, o movimento. $\mathbf{O}$ desenho,

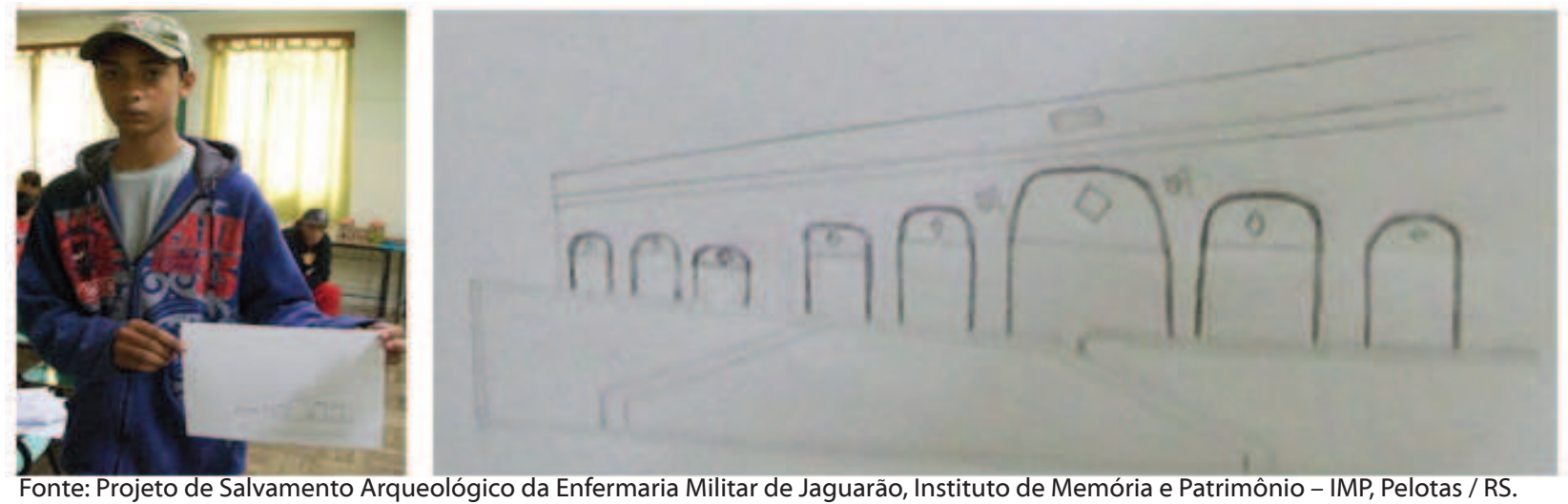

Figura 7 (detalhe)

Aluno da Escola Municipal de Ensino Fundamental Manuel Pereira Vargas., Jaguarão/RS, apresenta desenho do Mercado Público Municipal. 


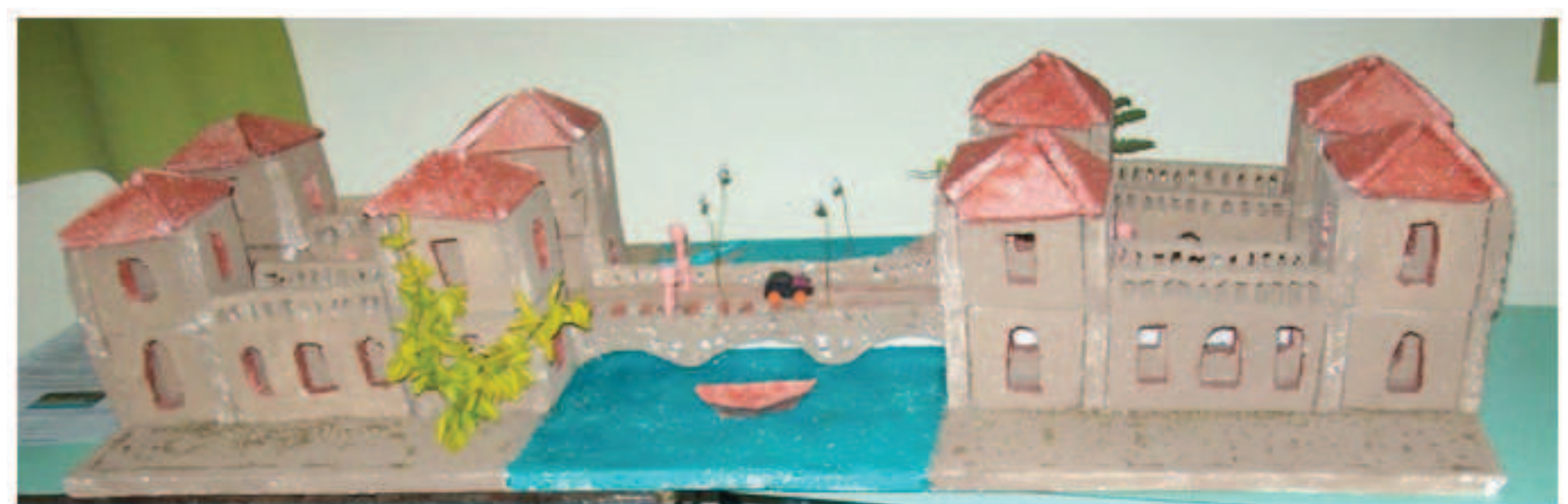

Fonte: Projeto de Salvamento Arqueológico da Enfermaria Militar de Jaguarão, Instituto de Memória e Patrimônio - IMP, Pelotas / RS.

\section{Figura 8}

Maquete confeccionada por alunas da E.M.E.F Manuel Pereira Vargas, Jaguarão/RS.

U M A CONDIÇÃ O:

PESQUISA PRÉ VIA

DAS FORMAS E

Nesse sentido, a metodologia a ser seguida em projetos de educação patrimonial deveria levar em conta algumas diretrizes, no que se refere à conceituação de Patrimônio cultural e suas implicações sociais (CERQUEIRA, 2005: 95-96)

1. A indissociabilidade entre o patrimônio humano e natural na conceituação do Patrimônio Cultural, de modo que as pesquisas, intervenções e políticas públicas sejam pensadas de forma integrada.

2. As especificidades e interfaces que marcam as diferentes relações entre o patrimônio tangível (material) e intangível (imaterial).

3. Valorização da cultura material e do patrimônio arqueológico como expressões de notável valor do Patrimônio cultural da humanidade, e que ao mesmo tempo nos dão acesso às pessoas comuns, muitas vezes ofuscadas ou obliteradas na documentação escrita oficial.

Atrás de cada artefato há uma pessoa, ou muitas pessoas. Descobrir quem eram e como viviam é um fator fundamental para a experiência humanizante que nos é proporcionada pelos objetos do patrimônio cultural. (PARREIRAS HORTA, 1991: 12)

Tanto os documentos escritos quanto a Cultura material são produtos de uma mesma sociedade, mas não são necessariamente complementares ou convergentes, pois o documento escrito representa as ideais ou interesses subjetivos de seu autor, à diferença da Cultura material. (...) Os documentos escritos informam-nos sobre as ideias de seus autores, em geral pertencentes a uma minoria dos que sabem ler e escrever. A escrita, assim, é um instrumento de poder de classe. A Cultura material, por outro lado, é o resultado, em grande parte, do esforço das pessoas comuns e conserva-se, muitas vezes, sem que assim se queira ou planeje, como testemunhos involuntários da história. (FUNARI, 2003: 40) 
4. O abandono da conceituação elitista de patrimônio, que o identificava com a visão hegemônica de grupos dominadores do passado, em favor de uma visão plural, que dê conta da diversidade sócio-cultural existente nas sociedades do passado, assim como do presente. Nesta perspectiva, patrimônio não é mais visto como sinônimo da excepcionalidade, da erudição, da genialidade. Hoje sem que isto implique perder o gosto pelo excepcional, pelo monumental - falar de patrimônio significa sobretudo interessar-se pelo registro do comum, como memória da expressão cultural do homem comum e de sua vida corriqueira.

5. A preservação do patrimônio deve envolver as comunidades, pois o conhecimento e a identificação cultural são condicionantes para que estas se interessem pela salvaguarda de sua memória. Para tanto, é necessário que o patrimônio não seja abordado como algo distante, exógeno a estas comunidades, sendo para tanto necessário desenvolver mecanismos de escuta da percepção que estas têm de sua memória e patrimônio, de modo a desenvolver um programa de educação patrimonial capaz de fomentar a autoestima das comunidades. É de fundamental importância que os agentes envolvidos no processo conheçam e reconheçam o patrimônio local, para que a partir daí passem a valorizar e a preservar esse bem.

Entendemos que a preservação do Patrimônio Arqueológico, Cultural e Natural passa pela identificação dos indivíduos primeiramente como cidadãos, em que o desejo ou o impulso pela preservação não seja somente o ato de celebrar o "monumental" passado acadêmico, mas sim uma tentativa de promover novos valores baseados em uma concepção completamente transformada da tradição e patrimônio, ou seja, a reapropriação da cidadania. (TAMANINI, 1998: 192)

6. Um programa de educação patrimonial precisa alcançar um equilíbrio entre a bagagem de conhecimentos técnicos da equipe, balizados nas várias formas de conhecimentos universitários relativos às suas expressões culturais (Arquitetura, História, Arqueologia, Antropologia, etc.) e as percepções populares de seu legado e manifestações culturais. Busca-se um equilíbrio entre Ciência e Senso Comum, entre Erudito e Popular, numa perspectiva pluralista, humanista e universalizante. Mas, sem dúvida, há que prevalecer uma atitude intelectual de humildade:

Para estudar o passado de um povo, de uma instituição, de uma classe, não basta aceitar ao pé da letra tudo quanto nos deixou a simples tradição escrita. É preciso fazer falar a multidão imensa dos figurantes mudos que enchem o panorama da história e são muitas vezes mais interessantes e mais importantes do que os outros, os que apenas escrevem a história. (HOLANDA, 1985: 173-74)

7. Um programa de educação patrimonial deve estar atento às declarações da UNESCO referentes ao patrimônio imaterial e à diversidade cultural (Cf. Declarações de 2003 e 2005), bem como às cartas patrimoniais referentes à salvaguarda do Patrimônio cultural da humanidade (Cf. Cartas de Atenas, Veneza, Estocolmo e Lausanne), devendo desenvolver-se no espírito e cumprimento da legislação vigente no Brasil, no que se refere ao Patrimônio cultural em geral e arqueológico em específico, incluindo-se neste ponto a Educação Patrimonial (Cf. Lei do Tombamento - Decreto-Lei no 25, 1937; Lei do Sambaqui - Lei n 3.924, de 
1961; Constituição de 1988, artigo 216; Portaria da Arqueologia de Contrato e da Educação Patrimonial - Portaria IPHAN n 230 de 2002). (SANTOS JÚNIOR, 2005: 01 015. SOARES, 2007. SOUZA, 2006. MONTICELLI, 2005. CERQUEIRA, CUNHA, 2007).

Há que se considerar ainda que a educação patrimonial exerce um papel no desenvolvimento regional, tanto do ponto de vista social - pois valoriza as identidades dos diferentes grupos que compõem a sociedade, estimulando sua autoestima social - quanto econômico - revertendo-se em importante impacto sobre o desenvolvimento de turismo com enfoque no patrimônio. Um programa pode vir a alimentar assim o turismo, que emerge como possibilidade para a sustentabilidade, de forma integrada, da preservação das diferentes manifestações do patrimônio cultural e ambiental.

O patrimônio, assim como a educação patrimonial, exige uma abordagem multifacetada, demandando a atuação de profissionais com formação em áreas variadas. Em vista disso, é salutar compor uma equipe com formação multidisciplinar, seus integrantes possuindo formação em áreas tais como: Antropologia, Arqueologia, Artes, História, Arquitetura, Design, Geografia, Turismo, Museologia, Literatura, Teatro, Música e Pedagogia.

É importante ressaltar que os projetos devem buscar, nas práticas com as crianças, um foco na ludicidade, sendo o lúdico fundamental no processo de ensino/aprendizagem, tanto no que diz respeito à educação de crianças como também na educação de adultos. (Figura 9 e 10)

A ludicidade é uma necessidade do ser humano em qualquer idade e não pode ser vista apenas como diversão. O desenvolvimento do aspecto lúdico facilita a aprendizagem, o desenvolvimento pessoal, social e cultural, colabora uma boa saúde mental, facilita os processos de socialização do conhecimento. (SANTOS, 1997: 12)
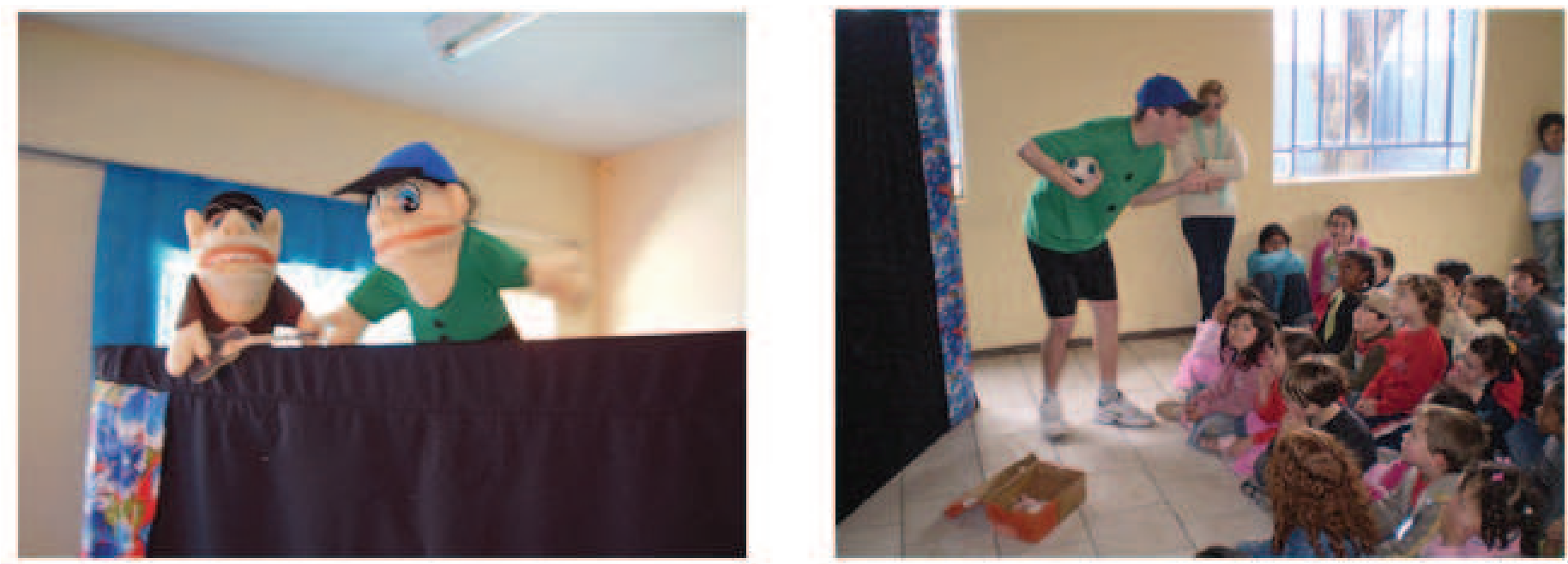

Fonte: Banco Cultural - Programa Memoriar - LEPAARQ/UFPEL

Figura 9 e 10

Teatro de Fantoches. Alternativa lúdica para se abordar o papel dos objetos na memória.

A necessidade do desenvolvimento da educação patrimonial na escola ligase à formação de cidadania com qualidade, preocupada com o fortalecimento da identidade cultural sustentada na memória das expressões culturais dos diferentes 
${ }^{3}$ Os temas locais, tradicionalmente tratados na terceira e quarta série, passam, dentro do novo sistema, com o ensino fundamental perfazendo nove anos, a ser abordados no quarto e quinto ano.

CONSIDERAÇÕ E S

F I N A IS grupos que compõem e compuseram a sociedade. (CERQUEIRA, 2005: 99-100)

A educação patrimonial precisa ser desenvolvida de forma criativa e participativa, sendo positiva sua inserção entre as atividades extra-curriculares. O processo de ensino-aprendizagem na educação patrimonial beneficia-se do dinamismo, marcado, por parte dos educandos, pela sua participação em um processo investigativo (LIPMAN, 1995: 66), que permite ao mesmo tempo associar suas experiências pessoais e familiares com as experiências coletivas expressas pelo patrimônio cultural. Beneficia-se ainda de um processo educativo que saia da rotina, que circule, que ande pela cidade, para gerar uma interação de olhares entre a escola e a cidade baseada numa "leitura estática, sensível e crítica do cotidiano". (GALVANI, 2005: 147) Os professores precisam ser preparados para enfrentar esse novo desafio. Para tanto, com o fito de dar continuidade aos projetos de educação patrimonial, é necessário que conheçam os conceitos e a legislação nacional atinente à preservação do patrimônio cultural, assim como as experiências já realizadas em outras escolas.

É comum que os projetos de educação patrimonial estejam focados nas escolas, e, sobretudo, nas escolas públicas. Dentro das escolas, dirigemse precipuamente às séries iniciais, uma vez que ali costumam ser ensinados aspectos de história local ${ }^{3}$. Há que se fazer uma série de ponderações sobre estas tendências, que podem assumir conseqüências negativas, mormente seus objetivos sejam nobres. Em primeiro lugar, é necessário frisar que todos os jovens, independente da classe social e natureza do ensino (público ou privado), devem ser colocados em contato com a educação patrimonial, do mesmo modo como é feito no que concerne à educação ambiental, pois todos deveriam ser no futuro cidadãos comprometidos com a preservação dos valores culturais das sociedades. Interessa que tanto trabalhadores quanto empresários sejam comprometidos com a preservação patrimonial.

De outro lado, restringir a educação patrimonial à população estudantil, e sobretudo, infantil, é um erro grave, pois os agentes sociais que estão atuando hoje, no mundo profissional, tomando decisões de ordem pública e privada, atuando nos movimentos sociais ou mesmo como consumidores, precisam, de forma urgente, ser sensibilizados, aproximados das questões patrimoniais: pode custar muito caro à preservação do patrimônio esperar que as atuais crianças se tornem adultos, para então reverter a tendência de perda dos valores e registros patrimoniais, dos suportes de identidade cultural coletiva, dos suportes de memória. Em 20 anos, sem cobranças e compromissos firmes por parte da comunidade adulta, muito do que hoje nos circunda como referenciais identitários e de memória social terá se esvanecido por completo, em certa parte pelo próprio processo natural do esquecimento, do apagar-se, mas, em grande parte, em decorrência da hegemonia social de interesses imobiliários, do lucro exasperado, bem como da falta de informação e das visões preconceituosas e elitistas de patrimônio.

Os projetos de Educação patrimonial possibilitam uma aproximação maior entre a população das comunidades envolvidas e os agentes promotores da sensibilização patrimonial, pertençam eles ao espectro universitário, ao setor público, ao terceiro setor ou mesmo à área de responsabilidade social do setor privado. Com isso, pretende-se melhorar a autoestima de regiões e populações que muitas vezes parecem não se enxergar como portadoras de uma memória 
extremamente importante para a constituição de sua história, a história de sua cidade, de seu estado, de seu país. Quer-se, também, promover o "empoderamento" destas comunidades portadoras de memória, para ocuparem seu espaço na seara política de construção e reconstrução do patrimônio cultural. Entendemos, em consonância com Ataídes e Machado (1998: 53), que "há necessidade de se criarem meios e mecanismos eficazes para que o cidadão comum tenha direito à cultura, à memória coletiva e tenha condições de apropriar-se desse patrimônio".

Do ponto de vista político, a prática da educação patrimonial implica um compromisso com os valores da pluralidade social e diversidade cultural (DECLARAÇÃO DA UNESCO SOBRE A DIVERSIDADE CULTURAL, 2001, Artigo 2 ), considerando as manifestações materiais e imateriais, eruditas e populares, invertendo assim a abordagem tradicional: a abordagem que privilegiava elementos patrimoniais relativos às elites pretéritas, o que por anos tem afastado setores populares da identificação com o que se reconhece publicamente como patrimônio cultural. 


\section{O C U M E N T A Ç Ã O}

DECLARAÇÃO UNIVERSAL DA UNESCO SOBRE A DIVERSIDADE CULTURAL. Resolução aprovada em 02 de novembro de 2001. Fonte: http://unesdoc.unesco.org/images/0012/001246/124687s.pdf

\section{B I B L I O G R A F I A}

ATAÍDES, Heloísa Selma Fernandes Capel de; MACHADO, Laís Aparecida. "Identidade cultural e memória - objetos de construção do patrimônio histórico". Revista de Divulgação Científica. Publicação do Instituto Goiano de Pré-história e Antropologia da Universidade Católica de Goiás. Goiânia, Editora UCG, vol. 2, p. 41-62, 1998.

CERQUEIRA, Fábio Vergara e CUNHA, Welcsoner Silva da. "Proteção legal do patrimônio arqueológico". In: I CONGRESSO INTERNACIONAL DA SAB. XIV CONGRESSO BRASILEIRO DE ARQUEOLOGIA. ARQUEOLOGIA, ETNICIDADE E TERRITÓRIO. FLORIANÓPOLIS, 2007. Anais (CD-ROM), 2007.

CERQUEIRA, Fábio Vergara. "Educação Patrimonial na Escola: Por que e Como?". In: CERQUEIRA, Fábio Vergara; GUTIERREZ, Ester Judite Bendjouya; SANTOS, Denise Ondina Marroni dos; MELO, Alan Dutra de (orgs) Educação Patrimonial: Perspectivas Multidisciplinares. Pelotas, Instituto de Memória e Patrimônio, 2008, p. 13-16.

CERQUEIRA, Fábio Vergara. "Patrimônio cultural, escola, cidadania e desenvolvimento sustentável". Diálogos. Revista do Departamento de História e do Programa de Pós-graduação em História da Universidade Estadual de Maringá, vol. 9, n. 1, p. 91-110, 2005.

CERQUEIRA, Fábio Vergara; MACIEL, Luísa Lacerda; ZORZI, Mariciana; SCHWANTZ, Jezuína.Kohls. "Entre o passado e o futuro: um encontro com a memória através dos objetos". Cadernos do CEOM, vol. 20, n. 26, p. 83-107, 2007.

CERQUEIRA, Fábio Vergara. "Proteção legal do Patrimônio Cultural e Arqueológico. Avanços e percalços no Brasil Contemporâneo". In: AXT, Gunter e SCHÜLER, Fernando (orgs.). Brasil Contemporâneo. Crônicas de um país incógnito. Porto Alegre, Ed. Artes e Ofícios, 2006, p. 345-375.

DERDYK, Edith. Formas de pensar o desenho: desenvolvimento do grafismo infantil. São Paulo, Scipione, 1989.

FUNARI, P.P. Arqueologia. São Paulo, Contexto, 2003.

FUNARI, Pedro Paulo e PELEGRINI, Sandra de Cássia Araújo. Patrimônio histórico e cultural. Rio de Janeiro, Zahar, 2006.

GALVANI, Maria Aparecida Magero. "Leitura da Imagem: uma interação de olhares entre a cidade e escola". Revista Educação e Realidade. vol. 30, n.2, p.145-163, 2005.

GONÇALVES, José Reginaldo Santos. "Ressonância, Materialidade e Subjetividade: as culturas como Patrimônios". Horizontes Antropológicos. Publicação do Programa de Pós-Graduação em Antropologia Social da Universidade Federal do Rio Grande do Sul. Porto Alegre, PPGAS, ano 10, n. 22, p. 15-36, 2004.

HOLANDA, Sérgio Buarque de. "Introdução às memórias de Thomas Davatz". In: DIAS, Maria Odila Leite da Silva (org.). Sérgio Buarque de Holanda. Coleção Grandes Cientistas Sociais, n. 51. São Paulo, Ática, 1985. p. 173-174.

LIMA FILHO, Manuel Ferreira; SILVEIRA, Flávio Leonel Abreu da. “Por uma antropologia do objeto documental: Entre a 'Alma das coisas' e a coisificação do Objeto." Horizontes Antropológicos. Publicação do Programa de Pós-Graduação em Antropologia Social da Universidade Federal do Rio Grande do Sul. Porto Alegre, PPGAS, vol.10, n. 22, p. 37-51, 2004.

LIPMAN, Matthew. A filosofia vai à escola. São Paulo, Summus, 1990.

MAGALHÃES, Aloísio. E triunfo? A questão dos bens culturais no Brasil. 2a ed. Rio de Janeiro, Nova Fronteira, Fundação Roberto Marinho, 1997.

MENDES, José Manuel Oliveira. “O desafio das identidades." SANTOS, Boaventura de Souza (org.). A Globalização e as Ciências Sociais. São Paulo, Cortez, 2002, p. 503-540.

MONTICELLI, Gislene. Arqueologia em Obras de Engenharia no Brasil: Uma Crítica aos Contextos. 2005. Tese de doutorado. Programa de Pós-Graduação em História, Pontifícia Universidade Católica do Rio Grande do Sul, Porto Alegre, 2005.

NUÑEZ, Débora Coimbra. Educação Patrimonial, nos bastidores do processo. A formação dos agentes multiplicadores e as metodologias de ensino aplicadas na apreensão de bens clturais: o caso de São João del Rei/Minas Gerais. 2011. Dissertação. Programa de Pós-Graduação em Memória Social e Patrimônio Cultural, Universidade Federal de Pelotas, Pelotas, 2011.

PARREIRAS HORTA, Maria de Lourdes. Educação patrimonial. Comunicação apresentada na Conferência Latino-Americana sobre Preservação do Patrimônio Cultural, jun. 1991. [cópia xerox]

SANTOS JÚNIOR, V. "A influência das cartas internacionais sobre as leis nacionais de proteção ao patrimônio histórico e pré-histórico e estratégias de preservação dos sítios arqueológicos brasileiros". Mneme, Caicó-RN, v. 6, n. 13, p. 01-015, 2005.

SANTOS, Santa Marli Pires dos (org.). O Lúdico na formação do educador. Rio de Janeiro, Vozes, 1997.

SOARES, Inês Virgínia Prado. Proteção jurídica do patrimônio arqueológico no Brasil: fundamentos para a efetividade da tutela em face de obras e atividades impactantes. Erechim, Habilis, 2007. 


\section{B I B L I O G R A F I A}

SOUZA, Marise Campos de. "Uma visão da abrangência da gestão patrimonial." In: MORI, Vitor Hugo; SOUZA, Marise Campos de; BASTOS, Rossano Lopes e GALLO, Haroldo (orgs.). Patrimônio: atualizando o debate. São Paulo, 9a SR/IPHAN, 2006.

TAMANINI, Elisabeth. "Museu, Arqueologia e o Público: um Olhar necessário". In: FUNARI, Pedro Paulo (org.) Cultura material e arqueologia histórica. Coleção Idéias. Campinhas, UNICAMP, 1998, p. 179-220.

ZAN, Dirce Djanira Pacheco e. "Currículo por projetos. Avanços e possibilidades". In: PARK, Margareth Brandini (org.). Formação de educadores: memória, patrimônio e meio-ambiente. Campinas, Mercado de Letras, 2003 p. 13-31. 